\title{
NUMERICAL STUDY ON PRESSURE DROP FACTOR IN THE VENT-CAP OF CDQ SHAFT
}

\author{
Bo SONG, Yanhui FENG, Xinxin ZHANG* \\ Department of Thermal Engineering, School of Mechanical Engineering \\ University of Science and Technology Beijing \\ Beijing, 100083, China \\ xxzhang@ustb.edu.cn
}

\begin{abstract}
In CDQ (Coke Dry Quenching) shaft, the vent-cap with complex structure is installed in the cone-shaped funnel under the cooling chamber. Besides supporting the descending coke in the chamber, it acts to introduce cooling gas uniformly to reduce the temperature fluctuation of cokes at outlet and realize stable operation of CDQ apparatus and. In this paper, the turbulent flow in vent-cap of CDQ experimental shaft of 1:7 real scale is numerically simulated by using CFD (Computational Fluid Dynamics) software, CFX. The velocity field, the outlet flux distribution and the pressure drop factor of each outlet under three kinds of vent-cap (called high vent-cap, low vent-cap and elliptic vent-cap) are analysed and compared. The results turn out that the pressure drop factor of elliptic vent-cap is lager than the other two ventcaps, and that the pressure drop factors of high vent-cap and low vent-cap almost have the same value. While for a specified vent-cap, the pressure drop factor with pressing brick is lager than that without pressing brick. The work in this paper is some valuable for the designing of vent-cap for large-scale CDQ shaft.
\end{abstract}

\section{INTRODUCTION}

Vent-cap has many important applications in industrial furnaces. For different furnaces, vent-cap has different shapes and different functions. But it commonly acts to distribute gas. Some vent-caps widely used in CFB boiler are depicted schematically in Fig $1^{[1]}$.

In CDQ (Coke Dry Quenching) shaft, the supplying gas system is composed of vent-cap, cross flue, up coneshaped funnel and down cone-shaped one. The vent-cap with complex structure is installed in the cone-shaped funnel under the cooling chamber. Besides supporting the descending coke, it acts to introduce cooling gas uniformly to reduce the temperature fluctuation of cokes at outlet and realize stable operation of CDQ apparatus ${ }^{[2]}$. The pressure drop of vent-cap is a significant factor in CDQ apparatus. The smaller the pressure drop of vent-cap is, the worse the uniformity of gas distributing is. On the contrary, large pressure drop increases power of the blower fan. So, the pressure drop is highly expected to be acquired to instruct the designing and operation of CDQ apparatus.

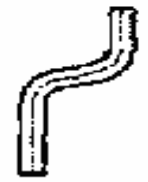

"pigtail” shape

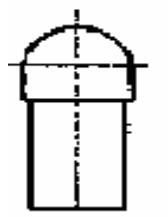

"bell cover" shape

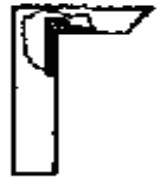

“figure 7” shape

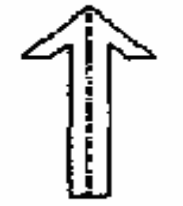

"arrow" shape
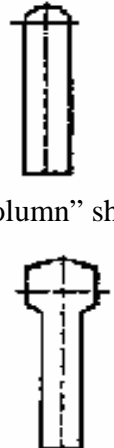

“mushroom” shape "column” shape

Figure 1. Various vent-cap structure

The pressure drop equation for vent-cap ${ }^{[1]}$ is showed in equation (1).

$\Delta P=\xi \cdot \rho \cdot \frac{v^{2}}{2}$

Where $\mathrm{v}(\mathrm{m} / \mathrm{s}), \quad \rho\left(\mathrm{kg} / \mathrm{m}^{3}\right)$ are the velocity and density of hot gas, respectively; $\xi$ is the pressure drop factor related to local geometry shape, roughness of solid wall and Reynolds number. Local geometry shape is always a dominant factor compared with other factors. So, $\xi$ is generally determined by local geometry shape.

Due to the complex structure of vent-cap, the pressure drop factor of vent-cap is not been calculated analytically but obtained experimentally. The experimental results by RenZhong et al. ${ }^{[3]}$ showed that the pressure drop factors were different for different vent-caps.

In this paper, we try to gain the pressure drop factor of CDQ vent-cap not by experimental or analytical study but by numerical simulation. The distributing gas system in CDQ shaft is numerically studied by introducing 1:7 scale model of one real CDQ shaft in some steel plant in China. Furthermore, two more vent-caps with different stuctures are proposed and analysed in this paper.

\section{PHYSICAL MODELS OF VENT-CAPS IN CDQ SHAFT}

Three kinds of vent-cap, called high vent-cap, low ventcap, and elliptic vent-cap respectively, are schematically illustrated in Fig. $2^{[2]}$. The relevant physical models under different pressing brick conditions are shown in Fig. $3 \sim 5$. 
The discretization meshes are unstructured and grids in some local position are fined to improve simulation accuracy. Because the cross holder exists, each outlet is divided into four regions along circumferential direction, A, B, C and D (starting from the front part of figure, clockwise). The specified region of each outlet is labelled by number and related letter. For example, " $1 \mathrm{~A}$ " indicates region A of outlet1. Two plane flues near the inlet (marking out by imaginal curve in Fig.3(a)) experience three conditions: without pressing brick, with transverse pressing brick and with longitudinal pressing brick, just as presented in Fig.6.

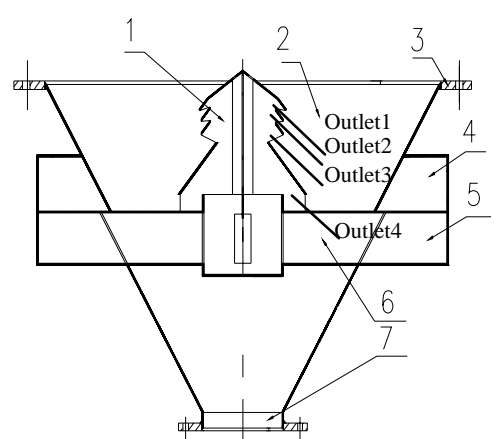

(a)

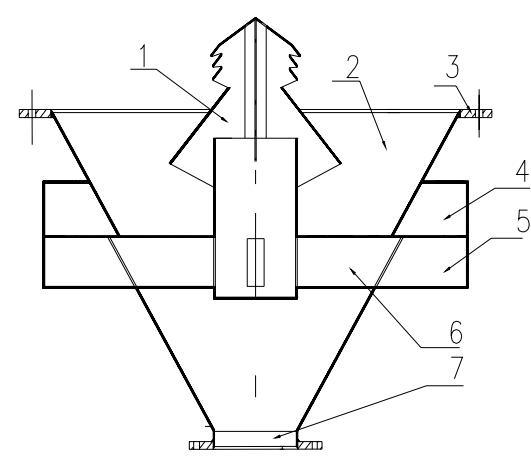

(b)

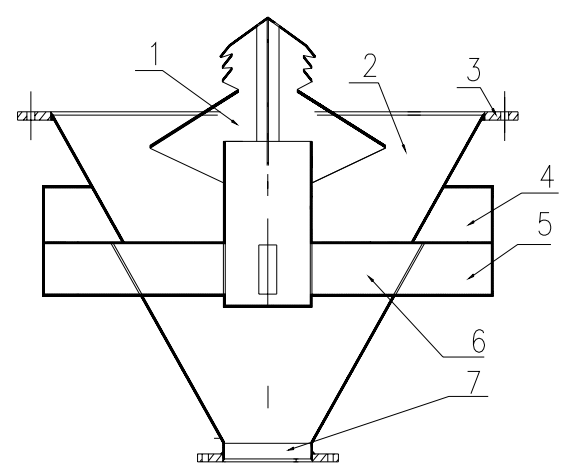

(c)

Figure 2. The experimental vent-cap structure (a) low vent-cap (b) high vent-cap (c) elliptic vent-cap (1-vent-cap, 2-down coneshape funnel, 3-flange, 4-gas supply of annular gap, 5-central gas supply, 6-gas flue, 7-exit )

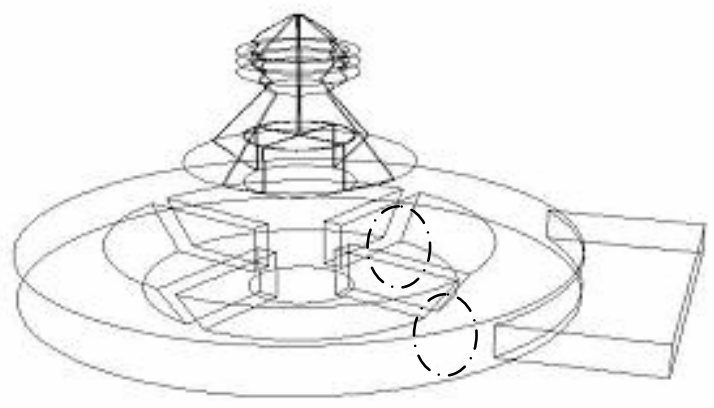

$\frac{1}{2}^{r} \cdot x$

(a) Geometry model

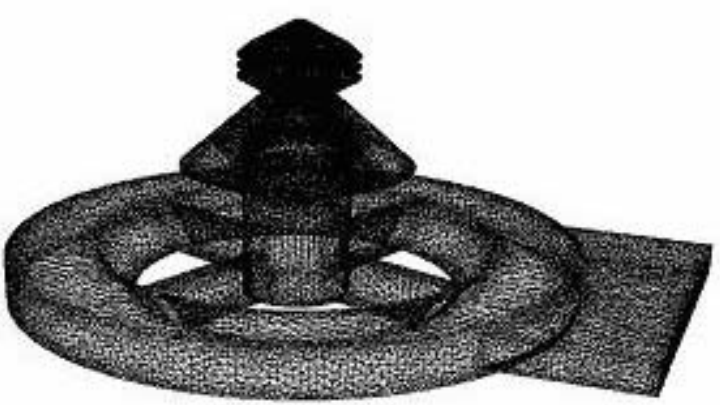

$\frac{1}{\tan x}$

(b) Mesh distribution

axas:

Figure 3: Model of high vent-cap

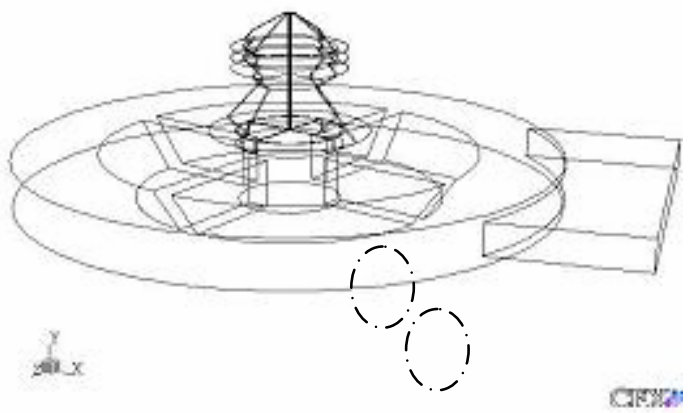

(a) Geometry model

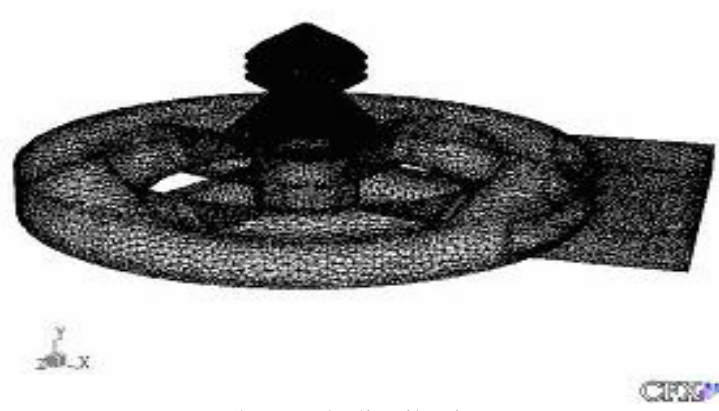

(b) Mesh distribution

Figure 4: Model of low vent-cap 


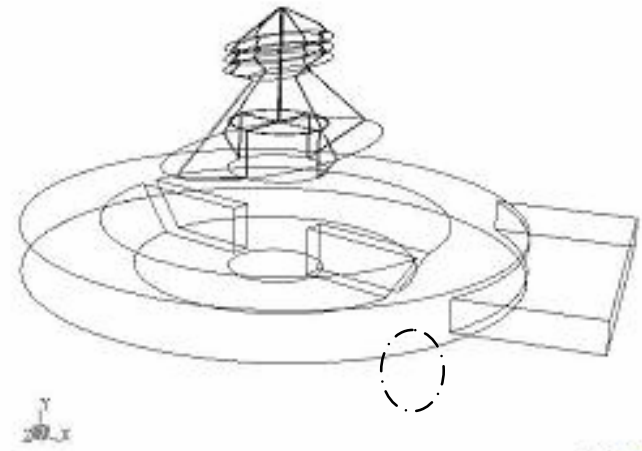

(a) Geometry model
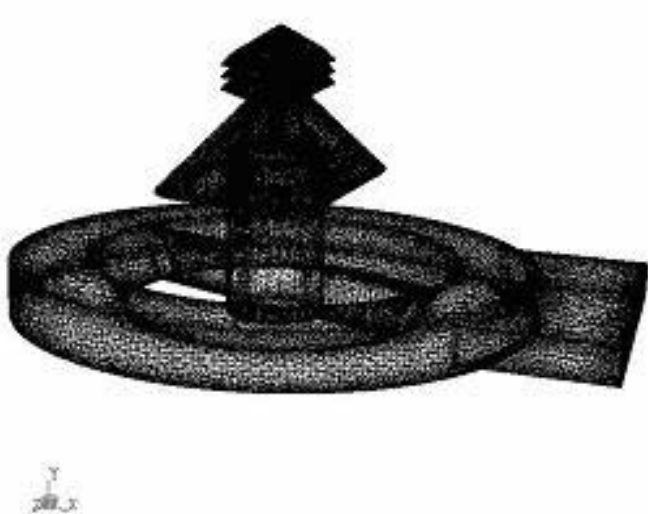

(b) Mesh distribution

Figure 5: Model of elliptic vent-cap

(1)

(2)

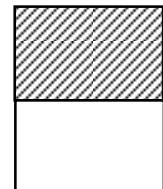

(1) without pressing brick, (2) with transverse pressing

brick, (3) with longitudinal pressing brick

Figure 6: Schematic of pressing brick state (shade area dedicates pressing brick)

\section{MATHEMATICAL FORMULATION AND BOUNDARY CONDITIONS}

Three-dimensional governing equations under steady state for the turbulent flow in vent-cap are given as follows ${ }^{[4]}$ :

The continuity equation: $\nabla \cdot(\rho U)=0$

The momentum equation:

$\nabla \cdot(\rho U \otimes U)-\nabla \cdot\left(\mu_{e f f} \nabla U\right)=\nabla P^{\prime}+\nabla \cdot\left(\mu_{e f f} \nabla U\right)^{T}+B$

The $k$ equation

$\nabla \cdot(\rho U k)=\nabla \cdot\left[\left(\mu+\frac{\mu_{t}}{\sigma_{k}}\right) \nabla k\right]+P_{k}-\rho \varepsilon$

The $\varepsilon$ equation:

$\nabla \cdot(\rho U \varepsilon)=\nabla \cdot\left[\left(\mu+\frac{\mu_{t}}{\sigma_{\varepsilon}}\right) \nabla \varepsilon\right]+\frac{\varepsilon}{k}\left(C_{\varepsilon_{1}} P_{k}-C_{\varepsilon_{2}} \rho \varepsilon\right)$

$$
\begin{aligned}
& P_{k}=\mu_{t} \nabla U \cdot\left(\nabla U+\nabla U^{T}\right)-\frac{2}{3} \nabla \cdot U\left(3 \mu_{t} \nabla \cdot U+\rho k\right)+P_{k b}, \\
& P_{k b}=\frac{\mu_{t}}{\operatorname{Pr}_{t}} \rho \beta g \cdot \nabla T, P^{\prime}=P+\frac{2}{3} \rho k \mu_{e f f}=\mu+\mu_{t}, \\
& \mu_{t}=C_{\mu} \rho \frac{k^{2}}{\varepsilon}, C_{\mu}=0.09, \sigma_{k}=1.0, \sigma_{\varepsilon}=1.3 \\
& C_{\varepsilon_{1}}=1.44, C_{\varepsilon 2}=1.92 .
\end{aligned}
$$

Where $B$ is the sum of body forces, $C_{\mu}, C_{\varepsilon_{1}}, C_{\varepsilon 2}, \sigma_{k}$, $\sigma_{\varepsilon}$ experiential constants, $\rho$ gas density $\left(\mathrm{kg} / \mathrm{m}^{3}\right), \boldsymbol{U}$ the velocities vector $(\mathrm{m} / \mathrm{s}), k$ turbulence kinetic energy $\left(\mathrm{m}^{2} / \mathrm{s}^{2}\right)$, $\varepsilon$ turbulence dissipation rate $\left(\mathrm{m}^{2} / \mathrm{s}^{3}\right), \mathrm{Pr}_{t}$ turbulent Prandtl number, and $\mu, \mu_{t}, \mu_{\text {eff }}$ are molecular (dynamic) viscosity, turbulent viscosity and effective viscosity, respectively(Pa-s); $P, P_{k}, P_{k b}$ are static pressure, the turbulence production due to viscous and buoyancy forces, the buoyancy production term, respectively $(\mathrm{Pa})$.

The gas $\mathrm{N}_{2}$ is the working fluid for CDQ system. The inlet temperature and density of gas are $126^{\circ} \mathrm{C}$ and $0.864 \mathrm{~kg} / \mathrm{m}^{3}$ respectively. The magnitude of gas inlet velocity is set to be $10 \mathrm{~m} / \mathrm{s}^{[5]}$ and its direction is assumed to be vertical to the pipe's cross section. The particles carried by gas are negligibly small. The solid wall is assumed to be nonslip. Heat Transfer is not considered in the case.

\section{NUMERICAL RESULTS AND ANALYSIS}

The streamline and the velocity contour of three vent-caps with different structures are shown in Fig 7 9. By streamlines, it is found that the interior flow is extremely complicated. By contours, it is seen that the gas supply with high vent-cap or low vent-cap is more uniform than that with elliptic vent-cap.

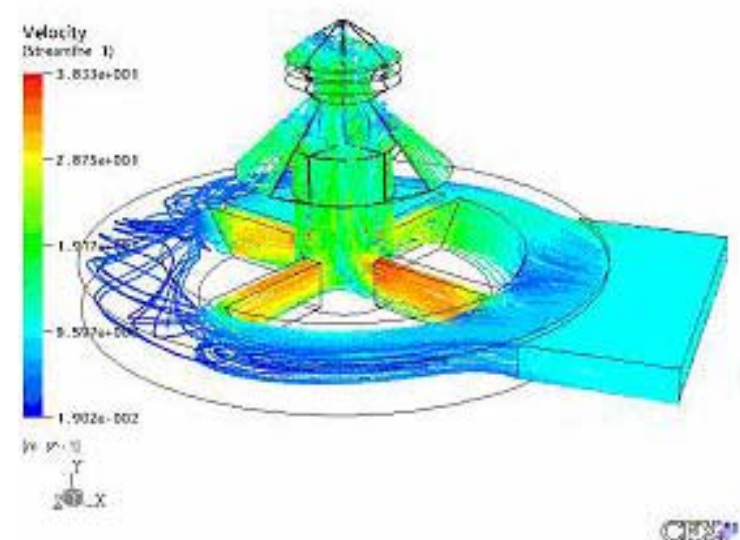

(a) Streamline without pressing brick

Where 


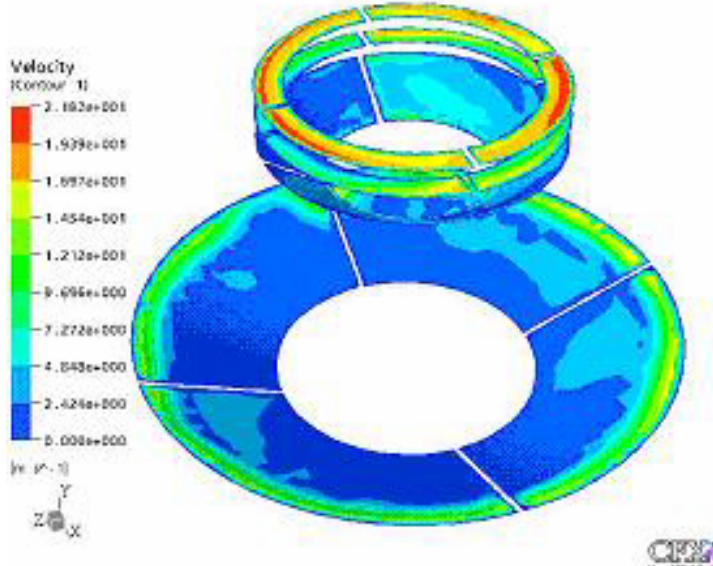

(b) Velocity Contour without pressing brick

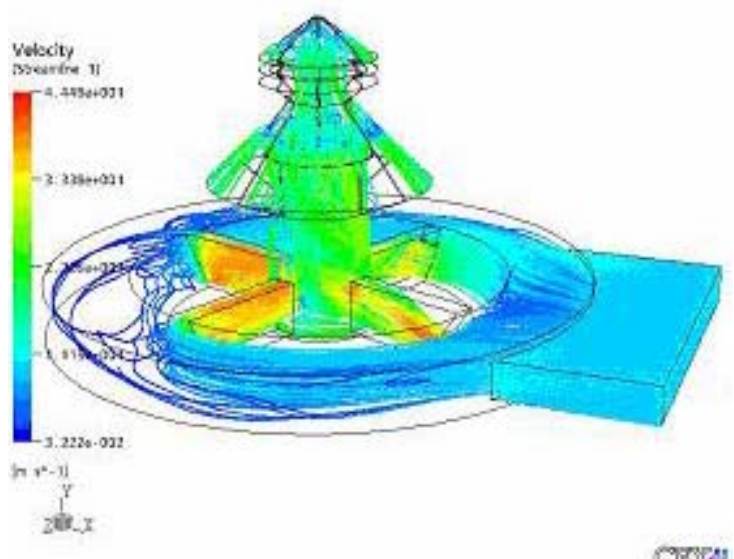

(c) Streamline with transverse pressing brick

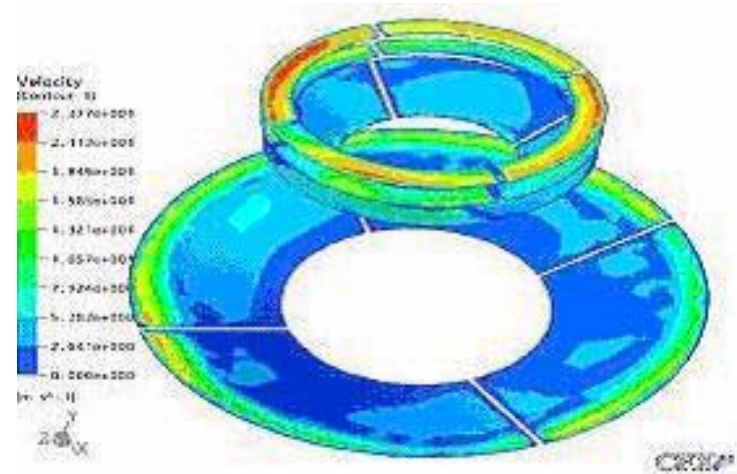

(d) Velocity Contour with transverse pressing brick

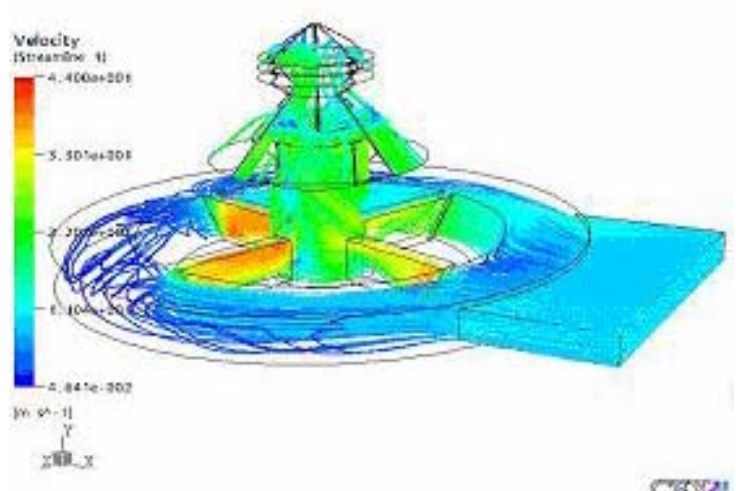

(e) Streamline with longitudinal pressing brick

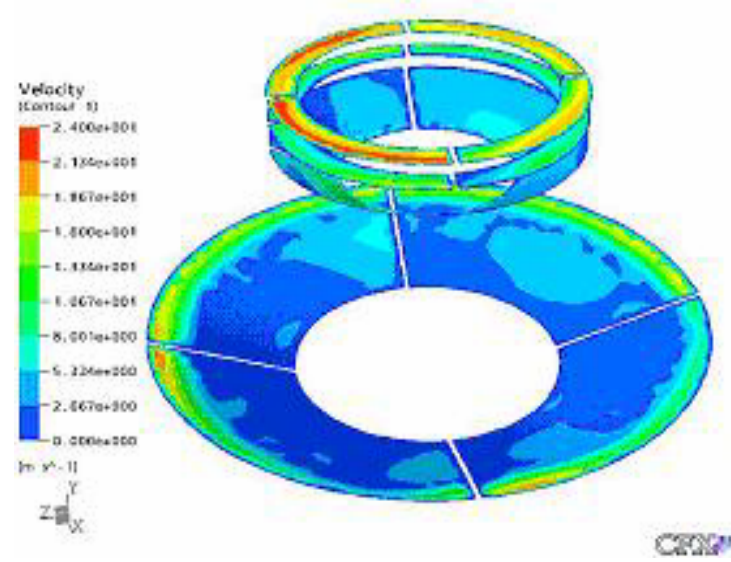

(f) Velocity Contour with longitudinal pressing brick

Figure 7: Streamline and Velocity Contour for high ventcap

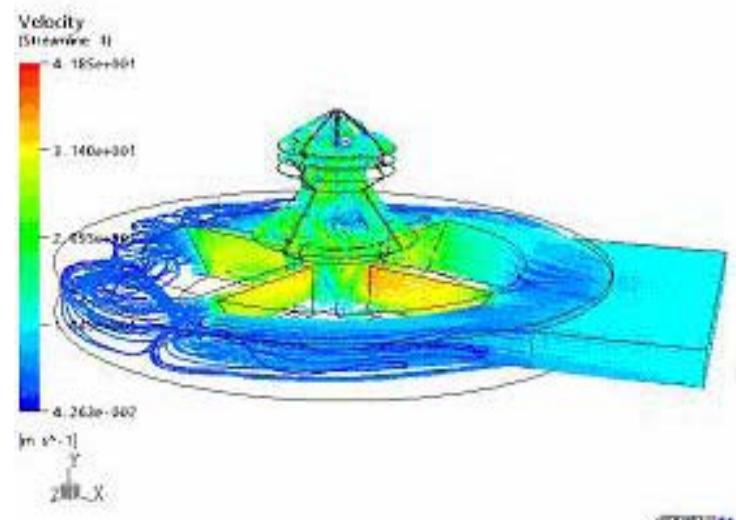

(a) Streamline without pressing brick

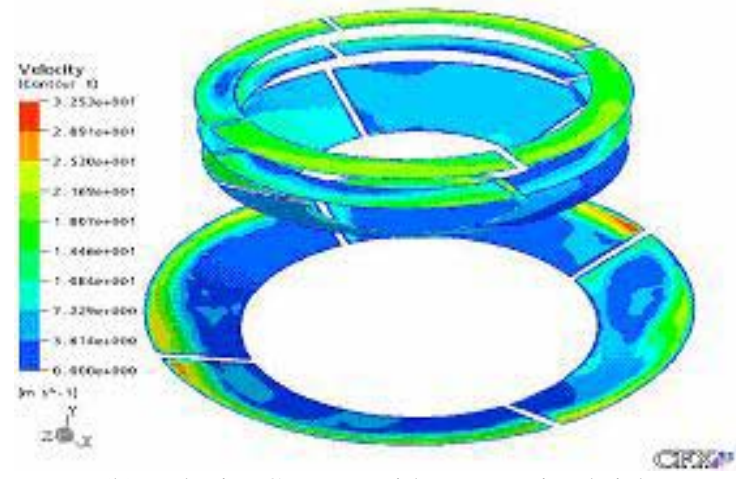

(b) Velocity Contour without pressing brick

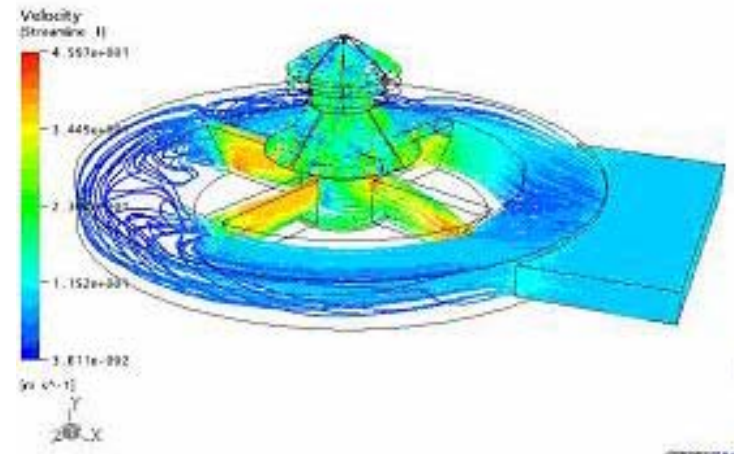

(c) Streamline with transverse pressing brick 


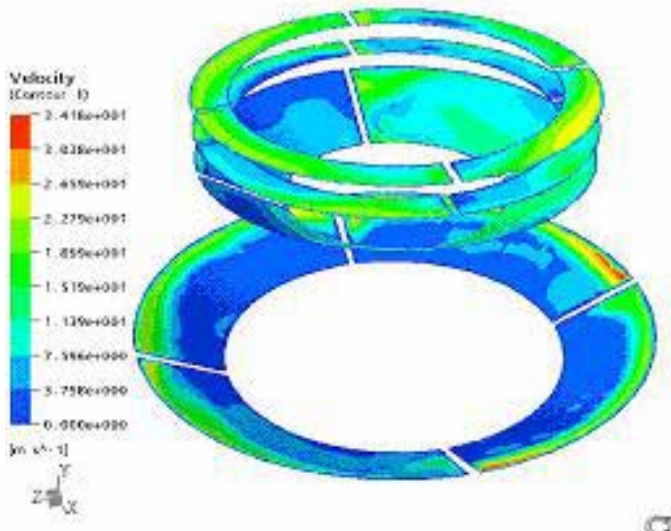

(d) Velocity Contour with transverse pressing brick

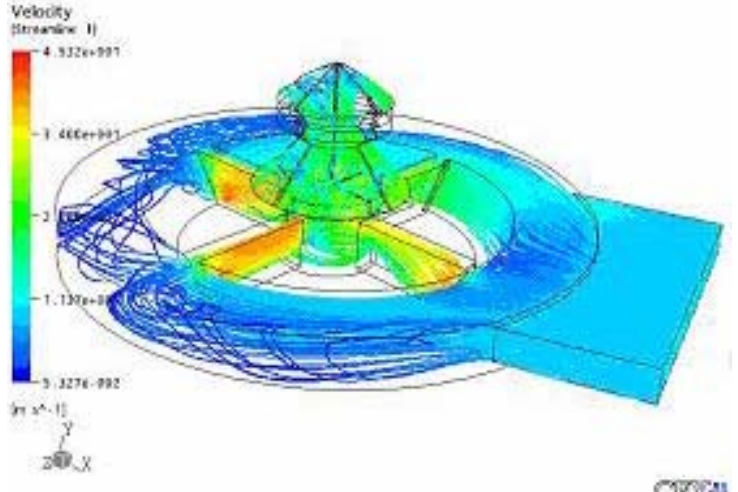

(e) Streamline with longitudinal pressing brick

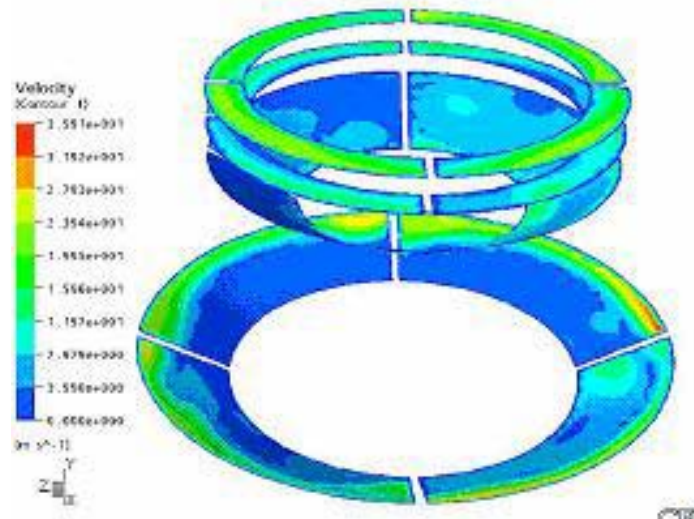

(f) Velocity Contour with longitudinal pressing brick

Figure 8: Streamline and Velocity Contour for low ventcap

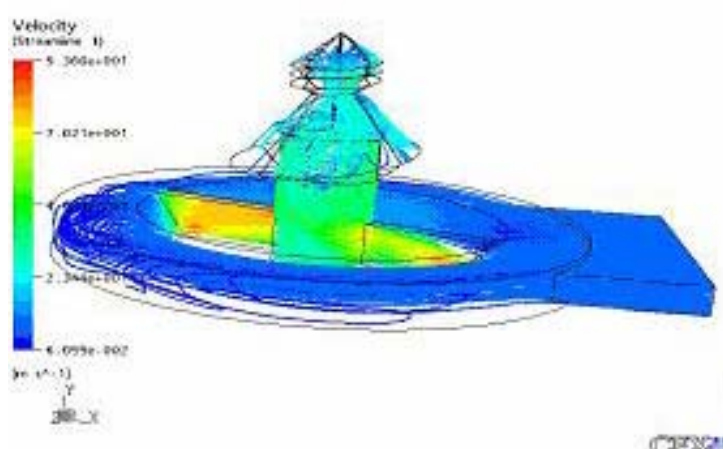

(a) Streamline without pressing brick

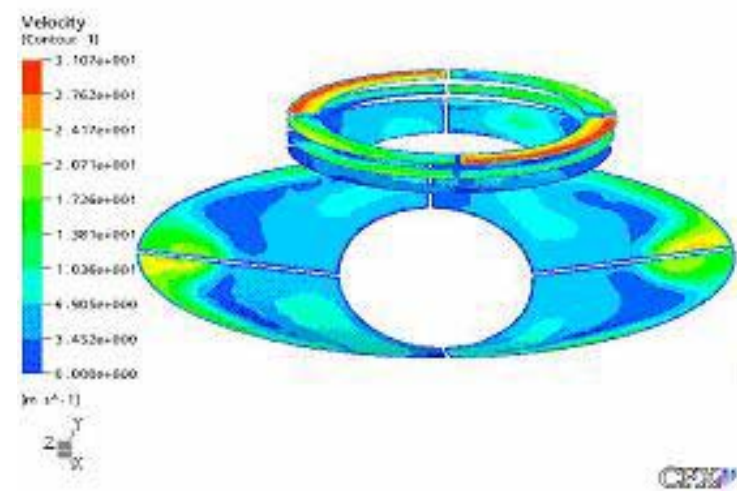

(b) Velocity Contour without pressing brick

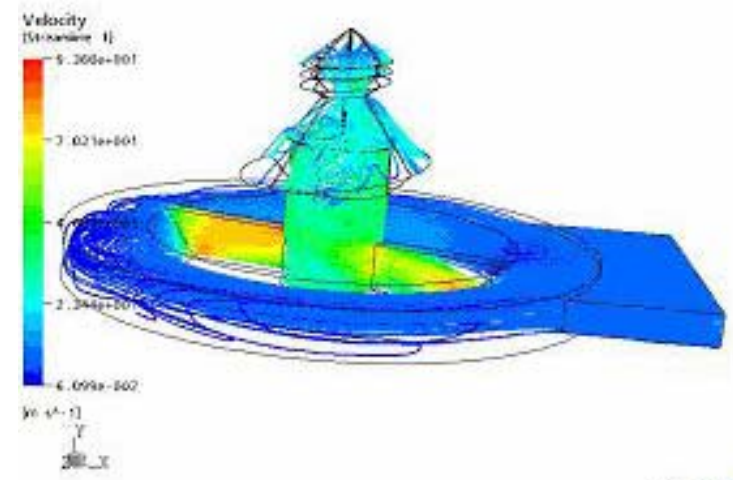

(c) Streamline with transverse pressing brick

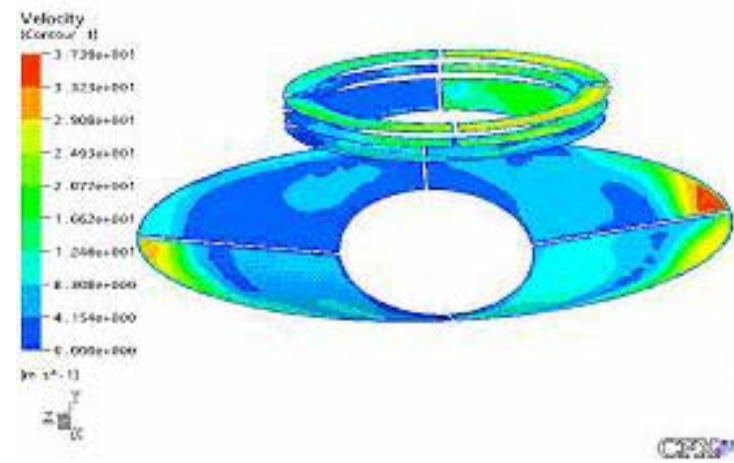

(d) Velocity Contour with transverse pressing brick

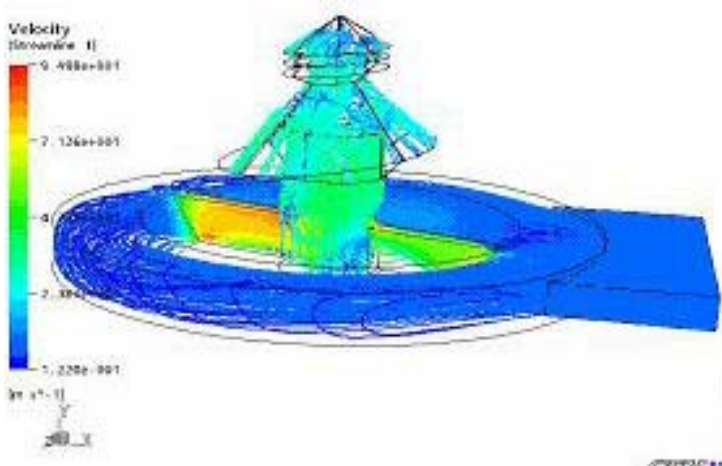

(e) Streamline with longitudinal pressing brick 


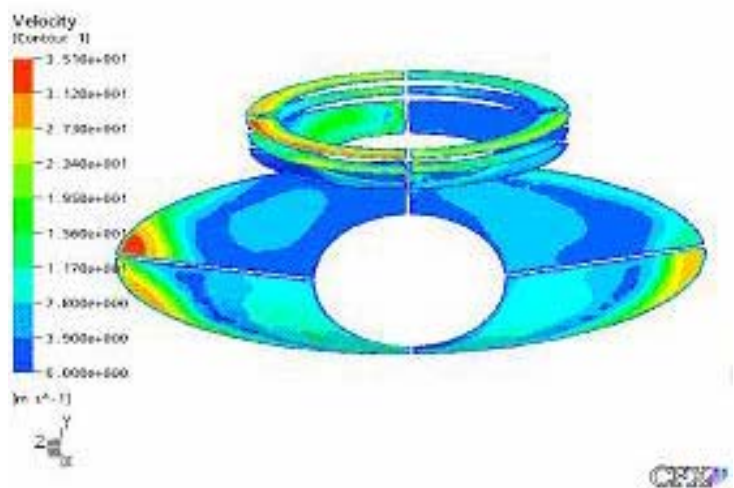

(f) Velocity Contour with longitudinal pressing brick

Figure 9: Streamline and Velocity Contour for elliptic vent-cap

Fig.10 17 indicates the pressure drop factors of three kinds of vent-caps under various pressing brick conditions. From Fig.10 and 14, it is obviously seen that the pressure drop factor of elliptic vent-cap is two times larger than that of high vent-cap and low vent-cap. This obviously set higher expectation on supplying gas apparatus. It is shown from other figures that vent-cap with transverse or longitudinal pressing brick will augment the pressure loss, which is expected to make the flow in vent-cap more complicated. In addition, the pressure losses augmented by transverse and longitudinal pressing brick are almost of the same magnitude.

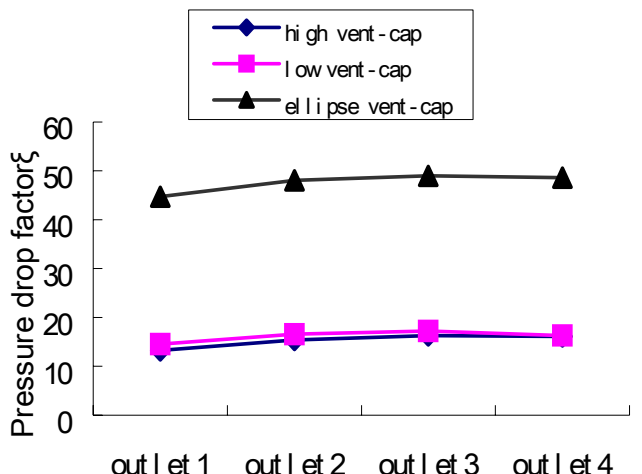

Figure 10. The pressure drop factors of three vent-caps without pressing brick
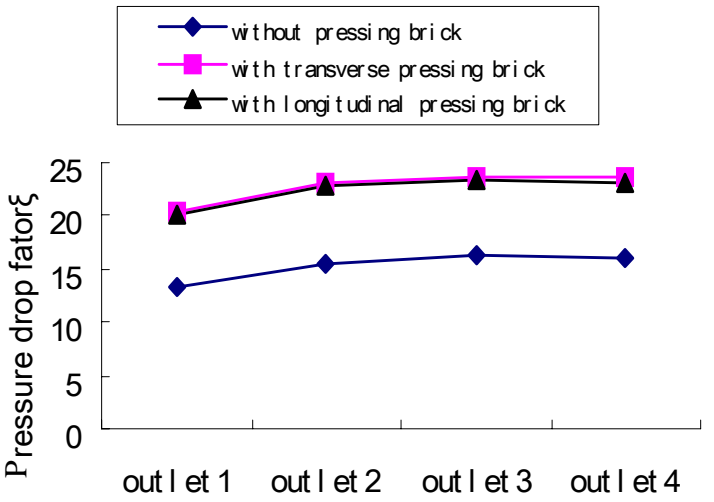

Figure 11. The pressure drop factors of high vent-cap

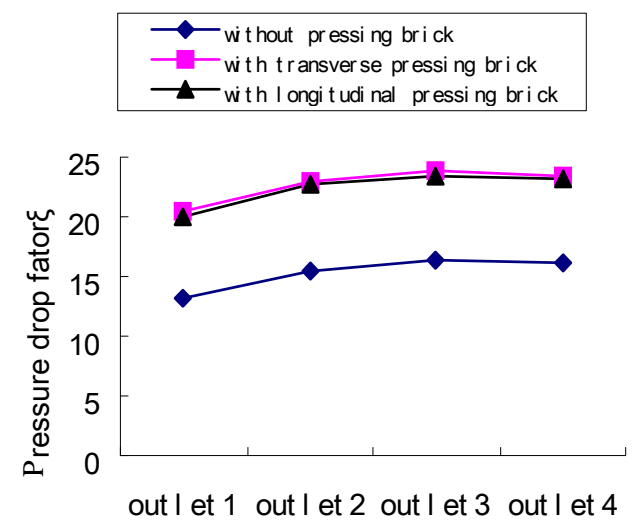

Figure 12. The pressure drop factors of elliptic vent-cap

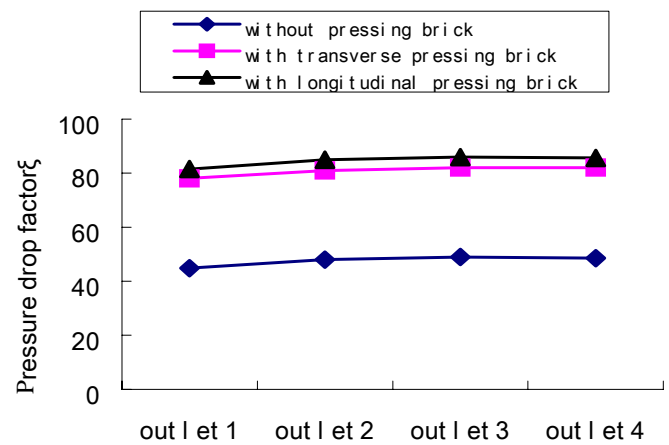

Figure 13. The pressure drop factors of low vent-cap

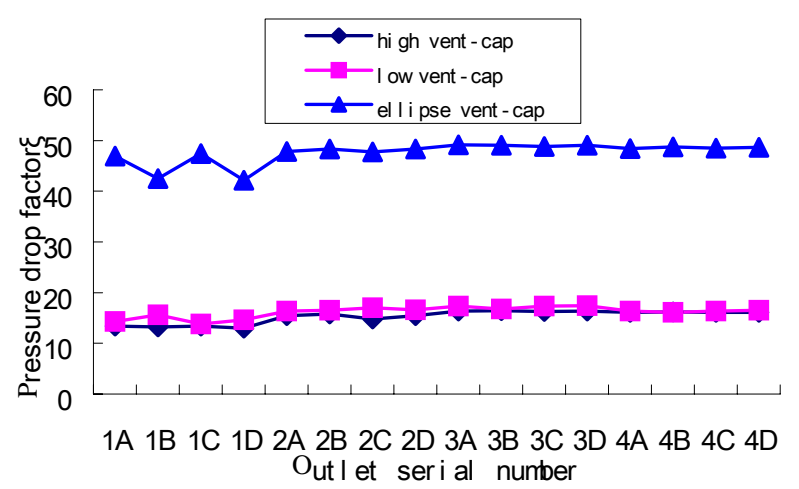

Figure 14. The pressure drop factor at each outlet for three vent-caps without pressing brick 


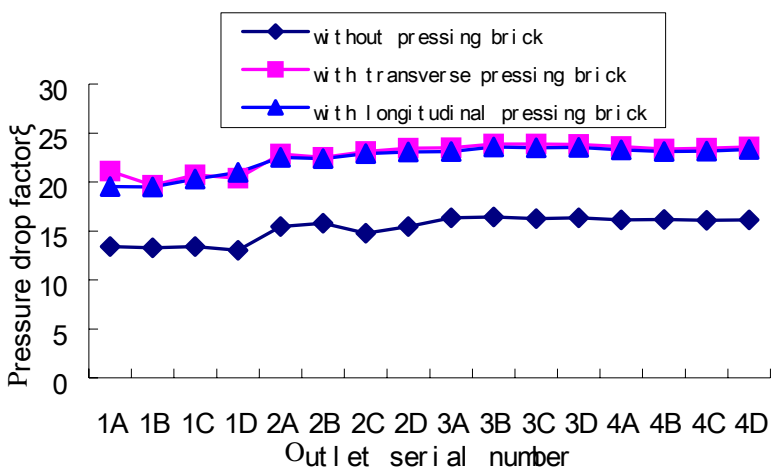

Figure 15: The pressure drop factor at each outlet for high vent -cap

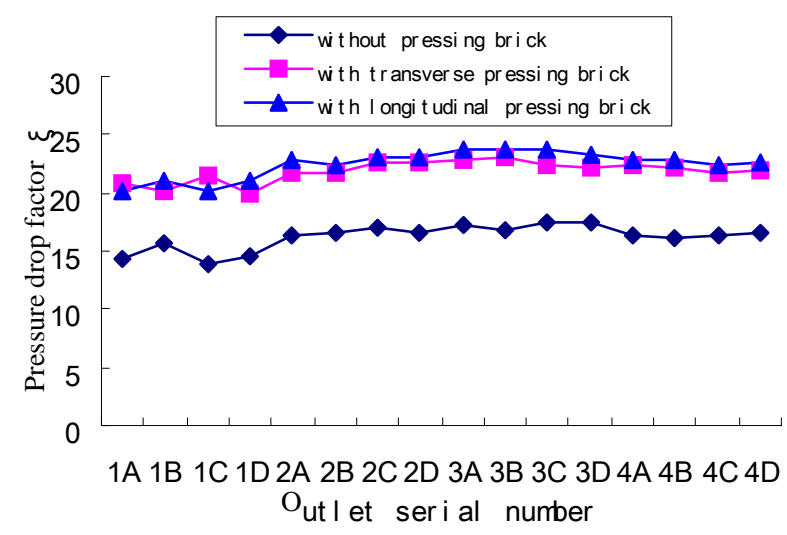

Figure 16: The pressure drop factor at each outlet for low vent -cap

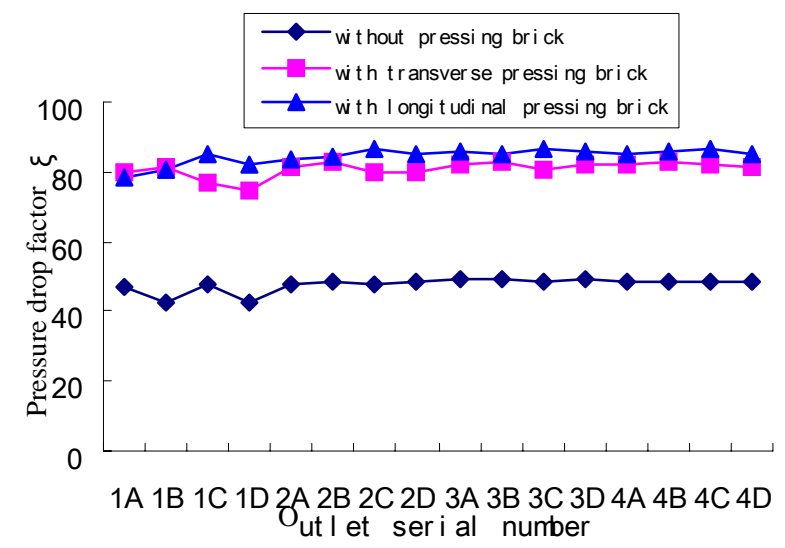

Figure 17: The pressure drop factor at each outlet for elliptic vent -cap

The mass flux at each outlet under different conditions is presented in Fig.18 21, respectively. One problem shown is that the pressures at outlet 3 are negative. It is known the negative pressure will make the coke powder engulfed into the vent-cap. However, on account of the small quantum, we think it doesn't bring too much trouble. The transverse or longitudinal pressing brick cannot obviously improve the uniformity of gas distribution for high ventcap and low vent-cap, while pressing brick clearly affects the gas distribution of elliptic vent-cap, though it is still far from the uniformity we expect. So further study is upon the look.

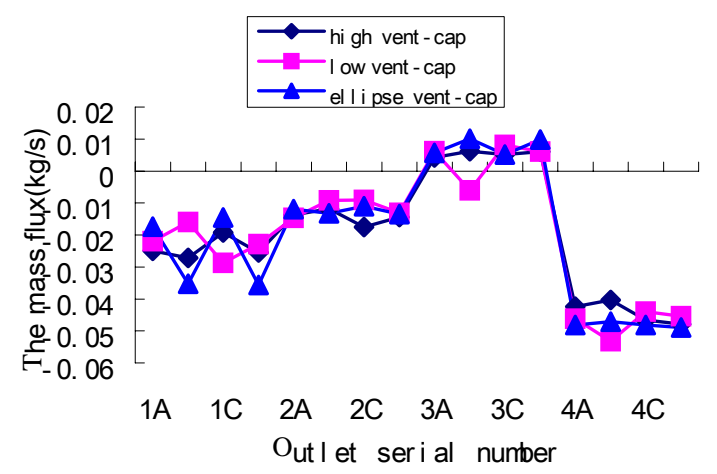

Figure 18: The mass flux at each outlet for three ventcaps without pressing brick

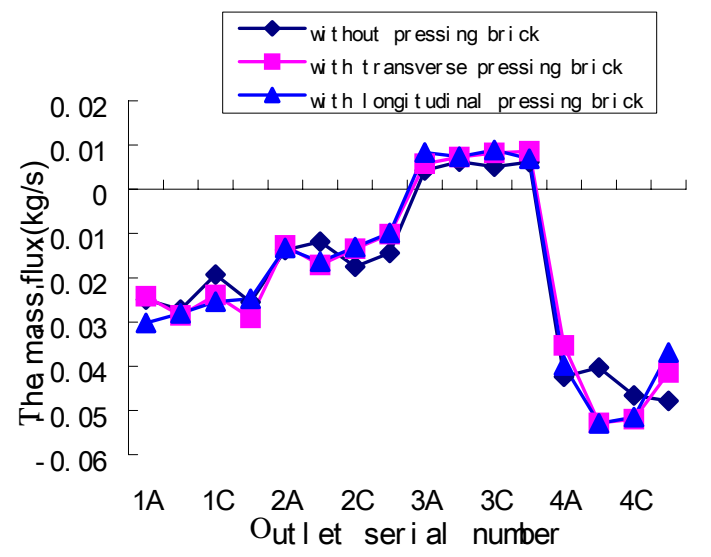

Figure 19: The mass flux at each outlet for high vent-cap

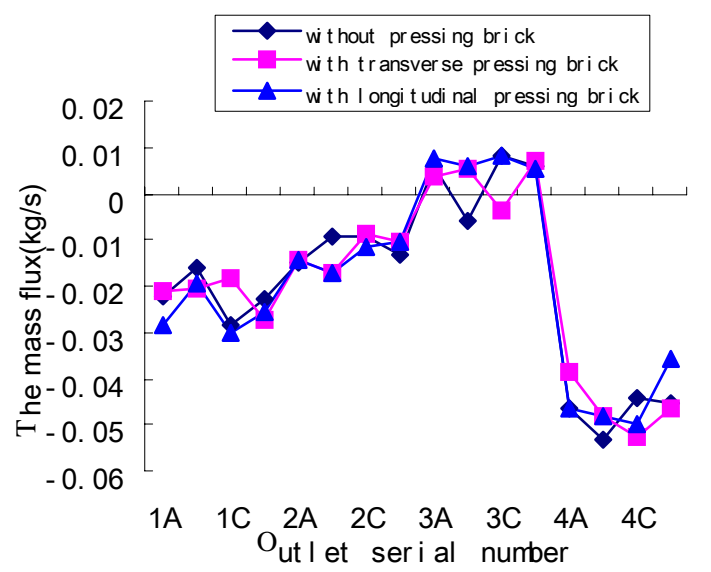

Figure 20: The mass flux at each outlet for low vent-cap 


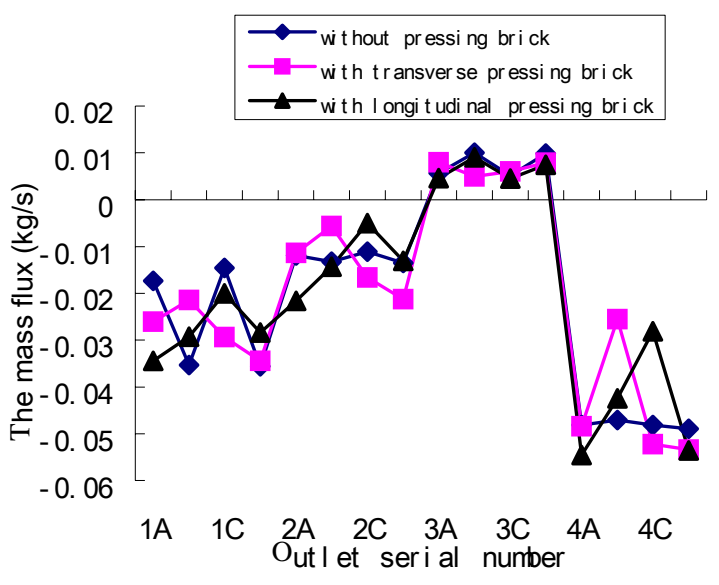

Figure 21: The mass flux of each outlet for elliptic ventcap

\section{CONCLUSION}

The turbulent flow in three types of vent-caps of CDQ shaft under different pressing brick conditions is numerically studied to obtain the relevant pressure drop factors. The model is built basing on 1:7 scale model of one CDQ real shaft in some steel plant in China. The main work in this paper includes:

1) The complicated velocity fields of various vent-caps are analysed and compared. It is found that the gas supply with high vent-cap and low vent-cap is more uniform than that with elliptic vent-cap.

2) The pressure drop factor at each outlet of vent-cap under different conditions is figured out by using the formula of local pressure drop loss. The results indicate that the negative pressure occurs at outlet 3 for any kind of vent-cap. Furthermore, the pressure drop factor of elliptic vent-cap is lager than the other two vent-caps, and the pressure drop factors of high vent-cap and low vent-cap almost have the same value. While for a specified vent-cap, the pressure drop factor with pressing brick is lager than that without pressing brick.

3) The future work is to verify simulate results by experiments .

\section{REFERENCES}

1 RenZhong, ZengGuang, HuangLiangcheng. The discussion about CFB boiler air-hood design. J Boiler manufacture.2005,3,1st.

2 ZhangHu, Experimental and Numerical Study on Coke Descending Behavior in CDQ Cooling Chamber, Thesis of master's degree, ustb. 2002.

3 RenZhong, ZengGuang et al. The experimental report of the air-hood resistance characteristic. Boiler plant in sichuan province .2003, (7).

4 GuoHongzhi, ZhangXinxin, LiuXiangjun, LiJie. Numerical simulation of transport process [M]. Metallurgical Industry Press, 1998.59-62.

5 Teplitskil M G,Gordon I Z,Kudryavaya N A et al. Coke Dry Quench [M]. LiZhehao et al. translated. Beijing: Metallurgical Industry Press, 1981. 4,122-130. 